\title{
The Irish Journal of Psychological Medicine: looking to the future
}

\author{
Brendan D Kelly
}

Ir J Psych Med 2010; 27(4): 170-171

Half a century ago, Dr Richard Asher, a physician at the Central Middlesex Hospital, London, famously posed a question: "Why are medical journals so dull?"1 There are many possible answers, not least of which is that many medical journal are not dull at all, but manage to maintain relevance, interest and impact over lengthy periods of time. The most successful journals achieve this by focusing on high quality content, adapting to technologies, and - most of all - adhering to a set of values that endures, even as societal, scientific and publishing environments change.

\section{The Irish Journal of Psychological Medicine}

The Irish Journal of Psychological Medicine was founded in 1982 by Dr Mark Hartman. The Journal was, from the outset, "an independent scientific voice", "innovative in its content", with a key role "in expressing the unique identity of Irish psychiatry." The journal grew in strength and popularity, and in 1994 Professor Brian Lawlor became Editor-in-Chief, following the untimely death of Dr Hartman.

From his appointment in 1994 until he stepped down in 2010, Professor Lawlor explicitly renewed the Journal's commitment to its central objectives: disseminating the results of original scientific research to a national and international readership; expressing "the unique identity of Irish psychiatry"; and "underscoring the important cross-cultural differences in psychiatry within and beyond these islands".

Over the following 16 years, the Journal published an increasing number of national and international research papers; circulation increased to 2,200 copies throughout 54 countries; format was substantially revised; and a website was developed, with full-text access to recent issues (www.ijpm.org).

In 1992, the Journal awarded the first John Dunne Medal, established in honour of Dr John Dunne, first Professor of Psychiatry in Ireland and President of the Royal MedicoPsychological Association in $1955 .^{3,4}$ In his inaugural address as president of the RMPA, Dr Dunne emphasised the "contribution of the physical sciences to psychological medicine" and endorsed a rigorous, broad-based approach to psychiatry:

"The various scientific approaches to the explanation of mental functioning by physiologists, neurologists,

"Brendan D Kelly, MD MA MSc MRCPI MRCPsych, Consultant Psychiatrist and Senior Lecturer in Psychiatry, Department of Adult Psychiatry, University College Dublin, Mater Misericordiae University Hospital, 62/63 Eccles Street, Dublin 7, Ireland.

Email brendankelly35@gmail.com

${ }^{*}$ Correspondence

SUBMITTED: OCTOBER 28. ACCEPTED: NOVEMBER 1, 2010. bio-chemists, electrologists, cyberneticists, not only appear to harmonize, even synchronize, in the elucidation of mental mechanistics, but also appear to harmonize very closely with the concepts of the psychological purist." ${ }^{5}$

Consistent with this approach, the John Dunne Medal is now awarded annually by the Irish Journal of Psychological Medicine. The prize is open to all trainees from Ireland, Northern Ireland and Britain. To be eligible, a trainee much have made a significant contribution (though not necessarily as first author) to an original paper published by the Journal over the year. Now approaching its 20th year, the John Dunne Medal has come to symbolise excellence and originality in the field of psychiatric research.

In 2004, the Journal appointed its first 'Trainee Editor', with a view to: (a) increasing the involvement of psychiatry trainees in the submission of original research papers, audit papers, and other articles; (b) optimising the Journal's relevance to trainees, by commissioning review papers on topics of relevance to trainees; and (c) involving the trainee editor in the wider editorial process at the Journal. ${ }^{6}$ This has been an extremely valuable initiative, both in terms of training and ensuring continuity within the Journal.

\section{The future of medical journals}

Today, it is readily apparent that medical journals face significant challenges, including the continual evolution of electronic communication technologies, issues related to independent peer-review processes and substantial changes in the publishing industry. ${ }^{7,8}$ Further issues relate to the complex roles of journals in the developing world ${ }^{9}$ and protection of human rights. ${ }^{10}$ Notwithstanding these challenges - or, more likely, because of them - medical journals appear set to retain a critical role in shaping medical knowledge, informing evidence-based practice, developing health policy and underpinning training in healthcare disciplines. ${ }^{11}$

These are particularly exciting times in the fields of psychiatry and mental health, owing chiefly to the development of more evidence-based approaches to treatment and continued advances in areas such as genetics, neuro-imaging and epidemiology. These advances further emphasise the necessity for innovative original research, rigorous editorial processes, and careful evaluation of the implications of such advances for clinical practice. The need for a reliable, peerreviewed forum is further underlined by significant changes in mental health policy and legislation in Ireland in recent years, deepening the need for careful debate about the implications of such changes for Irish psychiatry.

\section{Looking to the future}

In future years, the Irish Journal of Psychological Medicine aims to continue to pursue its core objectives, by continuing 
to publish innovative research and original scientific papers; providing a critical and constructive voice in psychiatry, both in Ireland and abroad; and helping shape the medical and scientific basis of developments in psychiatric practice.

The Journal will also build on new strengths. In June 2009 , we published the first of our Continuing Professional Development (CPD) modules, both in print and online. ${ }^{12}$ CPD is now a key element in the clinical activity of all health professionals and a cornerstone of good clinical governance throughout mental health services. The CPD policy of the College of Psychiatry of Ireland indicates that psychiatrists who participate in suitable online learning which fits the criteria for CPD may claim CPD points under the Personal CPD category (up to a maximum of 5 points per year).

This CPD section of the Irish Journal of Psychological Medicine provides CPD modules dedicated to key topics in mental health care. In order to assist with learning and selfassessment, multiple choice questions are provided at the end of each module. Each module and its multiple choice questions are available both in print and online (www.ijpm.org). Topics covered to date include the biological treatment of mood disorders, ${ }^{12}$ management of schizophrenia, ${ }^{13}$ management of alcohol use disorders, ${ }^{14}$ adherence in psychiatry, ${ }^{15}$ morbid jealousy ${ }^{16}$ and post-traumatic stress disorder. ${ }^{17}$ It is our intention to continue to develop and expand this section of the Journal in coming years. (Suggestions for future topics can be emailed to: psychological@medmedia.ie)

It is also our intention to develop and expand the Journal website further, to include enhanced presentation of CPD modules, original research, review papers and all articles published in the Journal. It is of particular note that the Journal continues to publish case reports, when many other journals have discontinued this practice. We believe that case reports serve several important purposes, including the description of new diseases and adverse effects; providing clues about new indications for existing treatments; ${ }^{18}$ and enhancing education and quality assurance. ${ }^{19}$ In addition, case reports are often especially engaging for readers, and this was a key consideration when the Lancet launched its series of peerreviewed case reports in $1995 .{ }^{20}$ Like the Lancet, the Irish Journal of Psychological Medicine still sees an important role for concise, relevant, well-written case reports.

The publication of case reports is consistent with the Journal's commitment to a plurality of paper formats, including editorials, original papers, brief reports, audits, case reports, systematic reviews, historical papers, CPD modules, letters to the editor and book reviews. This reflects the Journal's enduring objective to reflect the diversity of Irish psychiatry and, more specifically, the "complex tapestry of different historical traditions and experiences that mesh together to create a system that is unique and different from any of its derivative parts."2 Particular strengths include the Journal's commitment to publish historical papers ${ }^{21-23}$ and composite papers debating key issues in contemporary psychiatry. ${ }^{24,25}$

\section{Medical journals are not dull}

Towards the end of his consideration of the "dullness" of certain medical journals, $\mathrm{Dr}$ Asher concluded: "Style is what matters most".' We agree that style is critical, but also emphasise scientific rigour, clinical relevance, and clarity of thought. As the Irish Journal of Psychological Medicine approaches its 30th anniversary, it is our intention that a continued emphasis on these values will help develop, deepen and expand the role of the Journal even further. We look forward to your involvement and assistance in this process.

Declaration of Interest: Brendan D Kelly is Editor-in-Chief of the Irish Journal of Psychological Medicine. There is no other interest to declare.

\section{References}

1. Asher R. Why are medical journals so dull? British Medical Journal 1958; ii: 502-503.

2. Lawlor BA. Quo vadis? Irish Journal of Psychological Medicine 1994; 11: 107.

3. Reynolds J. Grangegorman: Psychiatric Care in Dublin since 1815. Dublin: Institute of Public Administration/Eastern Health Board, 1992

4. Kelly BD. Physical sciences and psychological medicine: the legacy of Prof John Dunne. Irish Journal of Psychological Medicine 2005; 22: 67-72.

5. Dunne J. The Contribution of the Physical Sciences to Psychological Medicine Journal of Mental Science 1956; 102: 209-220.

6. Kelly BD. Investing in the future. Irish Journal of Psychological Medicine 2004; 21 : 6. Kelly

7. Fletcher RH, Fletcher SW. The future of medical journals in the western world. Lancet 1998; 352: Suppl 2:SII30-3.

8. Horton R. 21 st-century biomedical journals: failures and futures. Lancet $2003 ; 362$ : 1510-1512.

9. Lown B, Bukachi F, Xavier R. Health information in the developing world. Lancet 1998; 352: Suppl 2:SII34-38.

10. Kandela P. Medical journals and human rights. Lancet 1998; 352: Suppl 2:SII711.

11. Vandenbroucke JP. Medical journals and the shaping of medical knowledge. Lance $1998 ; 352 ; 2001-2006$.

12. McDonald G, Hallahan B. Recent advances in the biological treatment of mood disorders (Continuing Professional Development, Module 1). Irish Journal of Psychological Medicine 2009; 26: 93-101.

13. Behan C. Current approaches to the management of schizophrenia (Continuing Professional Development, Module 2). Irish Journal of Psychologicał Medicine 2009 26: $157-163$

14. Feeney L. Management of alcohol use disorders (Continuing Professional Development, Module 3). Irish Journal of Psychological Medicine 2009; 26: 214-220.

15. Duffy R, Kelly BD. Adherence in psychiatry (Continuing Professional Development, Module 4). Irish Journal of Psychological Medicine 2010; 27: 54-60.

16. Mullins D. Morbid jeaiousy: the green-eyed monster (Continuing Professional Development, Module 5). Irish Journal of Psychological Medicine 2010; 27: 106-112.

17. Crumlish N. Post-traumatic stress disorder: present and future (Continuing Professional Development, Module 6). Irish Journal of Psychological Medicine 2010; 27: $162-167$.

18. Vandenbroucke JP. Case reports in an evidence-based world. Journal of the Royal Society of Medicine 1999; 92: 159-163.

19. Kelly BD. In defence of the single case report. Irish Medical Journal 2001; 94 : 37 20. Bignall J, Horton R. Learning from stories - the Lancet's case reports. Lancet 1995 346: 1246.

21. Breathnach CS. Philip Crapton (1777-1858) and his description of nominal aphasia Irish Journal of Psychological Medicine 2009; 26: 41-42.

22. Walsh D. The Ennis District Lunatic Asylum and the Clare Workhouse Lunatic Asylums in 1901. Irish Journal of Psychological Medicine 2009; 26: 206-211.

23. Kelly $\mathrm{BD}$. Learning disability and forensic mental healthcare in nineteenth-century Ireland. Irish Journal of Psychological Medicine 2008; 25: 116-118.

24. Lawlor B, Ganter K, Daly I, Owens J. Implementing the Mental Health Act 2001 : what should be done? What can be done? Irish Journal of Psychological Medicine 2005; 22: 79-82.

25. Kelly BD, Bracken P, Cavendish $H$, Crumlish N, MacSuibhne $S$, Szasz T, Thornton T. The Myth of Mental Illness 50 years after publication: what does it mean today? Irish Journal of Psychological Medicine 2010; 27: 35-43. 
